\title{
Association of the estrogen receptor- $\beta$ gene RsaI and AluI polymorphisms with human idiopathic thin endometrium
}

\author{
A.W. Le', Z.H. Wang ${ }^{1}$, R. Yuan ${ }^{2}$, L.L. Shan ${ }^{1}$, T.H. Xiao ${ }^{1}$, R. Zhuo ${ }^{1}$ and \\ Y. Shen ${ }^{3}$ \\ ${ }^{1}$ Department of Obstetrics and Gynecology, \\ Nanshan Affiliated Hospital of Guangdong Medical College, Shenzhen, China \\ ${ }^{2}$ Department of Obstetrics and Gynecology, \\ First Affiliated Hospital of Chongqing Medical University, Chongqing, China \\ ${ }^{3}$ Department of Obstetrics and Gynecology, Union Hospital, \\ Tongji Medical College, Huazhong University of Science and Technology, \\ Wuhan, China \\ Corresponding author: Y. Shen \\ E-mail: xiehesy@163.com
}

Genet. Mol. Res. 12 (4): 5978-5985 (2013)

Received November 22, 2012

Accepted August 20, 2012

Published November 26, 2013

DOI http://dx.doi.org/10.4238/2013.November.26.7

\begin{abstract}
The aim of this study was to investigate the potential correlation between polymorphisms of the estrogen receptor (ER)- $\beta$ gene (RsaI and AluI) and ethnic Han Chinese human idiopathic thin endometrium. A total of 120 patients with idiopathic thin endometrium and 120 sterility patients with normal endometrium thickness (controls) were included in the study. RsaI and AluI polymorphisms of the ER- $\beta$ gene were analyzed with polymerase chain reaction-restriction fragment length polymorphism. The distribution of polymorphisms, genotype, allele, and haplotype was compared between the 2 groups. A significant difference in the RsaI genotype was observed between idiopathic thin endometrium patients and controls. The distribution of the $\mathrm{R}$ allele of the $R s a \mathrm{I}$ polymorphism in idiopathic thin endometrium patients was $37.1 \%$ compared with $48.3 \%$ in controls. The odds ratio was $0.630(95 \%$
\end{abstract}


confidence interval $=0.438$ to $0.907, \mathrm{P}=0.013$ ). No significant difference in the genotype of the $A l u \mathrm{I}$ polymorphism was found between the two groups. The linkage disequilibrium between $R s a \mathrm{I}$ and $A l u \mathrm{I}$ haploids was not significant in either group, with D' values of 0.2036 and 0.0685 in the idiopathic thin endometrium patients and controls, respectively. The results of this study suggest a potential role of the ER- $\beta$ gene polymorphisms in the etiology of idiopathic atrophic endometrium and the $\mathrm{R}$ allele as a potential protective factor in ethnic Han Chinese.

Key words: Endometrium; Estrogen receptor; Allele; Gene polymorphism

\section{INTRODUCTION}

Normal endometrial thickness varies between 5 and $10 \mathrm{~mm}$ and changes during the menstrual cycle. The definition of normal and thin endometrium is controversial (Richter et al., 2007; Detti et al., 2008; Traub et al., 2009), with 6 to $9 \mathrm{~mm}$ (Kovacs et al., 2003; Singh et al., 2011) accepted as threshold values. A lining less than $6 \mathrm{~mm}$ can cause sterility (Setiawan et al., 2004; Momeni et al., 2011) and a lining less than $5 \mathrm{~mm}$ has been adopted as the diagnosis criteria for thin endometrium by Saha et al. (2004) through transvaginal ultrasound measurements. Patients with a thin endometrium of unknown etiology are classified as having idiopathic thin endometrium. The endometrium proliferates under the influence of estrogen and other hormones and with inadequate stimulation - for example, due to lack of estrogen or estrogen receptor (ER) - the endometrium remains thin and inactive (Mylonas et al., 2007). Our previous studies have shown that the ER gene in idiopathic thin endometrium patients is expressed at lower levels than that in healthy individuals. ERa gene $P v u \mathrm{II}$ and $\mathrm{XbaI}$ polymorphism has been related to idiopathic thin endometrium in a previous study (Yuan and Le, 2012). Furthermore, a polymorphism in the human ER- $\beta$ gene has been found within the 5 th exon RsaI site and the 8th exon 3' noncoding region AluI site as the common loci (Goumidi et al., 2011). Polymorphism has been postulated to have an effect on ER expression levels, thereby affecting its biological activity. In the current study, the PCR-restriction length polymorphism technique was used to explore the potential correlation between polymorphism of the RsaI and AluI sites (i.e.; polymorphisms recognized by RsaI and AluI restriction enzymes, respectively) and idiopathic thin endometrium.

\section{MATERIAL AND METHODS}

\section{Patients}

We selected 120 patients with idiopathic thin endometrium under care at the First Affiliated Hospital of Chongqing Medical University (Chongqing, China) from February 2004 to November 2006. These patients ranged in age from 19 to 42 years (mean, $30.6 \pm 3.1$ years). Another 120 sterility patients with normal endometrial thickness and ranging in age from 20 to 41 years (mean, $29.2 \pm 3.3$ years) were included as controls. Two subjects in both groups were ethnic Han Chinese. Menstrual cycles were 26 to 30 days long in both groups. The inclusion criteria for idiopathic endometrium were as follows: 1) normal serum sex hormone levels; 2) 
endometrium smooth and thin, as revealed by hysteroscopy, on days 15 to 20 of the menstrual cycle, with no adhesions in the uterine cavity and uterine opening of the fallopian tube visible; 3) endometrium thickness was less than $5 \mathrm{~mm}$ on days 15 to 20 of the menstrual cycle, as determined by ultrasound; 4) no other endocrine diseases such as diabetes, thyroid or adrenal disease, tuberculosis, or surgical or congenital disease; and 5) unrelated patient group without sex hormone therapy administration within the previous 3 months. The sterility controls met the criteria of endometrium thickness higher than $5 \mathrm{~mm}$ as well as the 1st, 4th, and 5th criteria for idiopathic thin endometrium. This study was approved by the First Affiliated Hospital of Chongqing Medical University, and written informed consent was obtained from every participant.

\section{Parameters for inclusion criteria}

Venous blood was collected from patients during the luteal phase in a fasting state. Enzyme-linked immunosorbent assay (Biocheck, USA) was conducted to determine the serum levels of sex hormones including follicle stimulating hormone, luteinizing hormone, estrogen, prolactin, progesterone, and testosterone according to manufacturer instructions. Endometrium thickness was measured using B ultrasound photography between the 15th and 20th day of the menstrual cycle.

\section{Analysis of RsaI and AluI polymorphisms of the ER- $\beta$ gene}

DNA was obtained from $2 \mathrm{~mL}$ peripheral blood of patients and controls using the phenol-chloroform extraction method. Polymorphisms were analyzed with polymerase chain reaction (PCR) and based on fragment size analysis. PCR was performed specifically to amplify the 5th and 8th exons of the ER- $\beta$ gene using following primers: 5'-TCTTGCTTTCCCCAGGCTTT-3' and 5'-ACCTGTCCAGAACAAGATCT-3' for the Rsa 1 site, and 5'-TTTTTGTCCCCATAGTAACA-3' and 5'-CCTCTGCTAACAAGGGAAA-3' for the AluI site, as described previously (Shapiro et al., 1993).

\section{Statistical analysis}

The SPSS13.0 software was used for the analysis. The gene count method was used for genotypes and allele frequency calculations. The 4-form chi-square test and $\mathrm{R} \times \mathrm{C}$ contingency table chi-square test were used for analysis of the agreement between the research objects, Hardy-Weinberg equilibrium, and comparison of individual genotypes and allele frequencies between groups. The relative risk was indicated by the odds ratio and $95 \%$ confidence interval. The 2 sets of measurements were compared with the $t$-test. A P value of $<0.05$ was considered to be statistically significant.

\section{RESULTS}

The serum concentration of 6 sex hormones (Table 1), average age, and induced abortion history (Table 2) were compared between the 2 groups. No significant differences between the groups were found for any of these parameters, indicating that both met the inclusion criteria. In this manner, we excluded the possibility that the thin endometrium resulted 
from abnormalities in the level of sex hormones or from induced abortion. As expected, the endometrium thickness of idiopathic thin endometrium patients was significantly lower than that of the controls $(\mathrm{P}<0.001$; Table 3$)$.

Table 1. Comparison of the serum levels of sex hormones in the two groups (means $\pm \mathrm{SD}$ ).

\begin{tabular}{lccc}
\hline Index & Case group $(\mathrm{N}=120)$ & Control group $(\mathrm{N}=120)$ & $\mathrm{P}$ \\
\hline E2 $(\mathrm{pg} / \mathrm{mL})$ & $70.79 \pm 32.26$ & $63.03 \pm 36.12$ & 0.633 \\
P $(\mathrm{ng} / \mathrm{mL})$ & $2.66 \pm 1.17$ & $2.39 \pm 0.75$ & 0.474 \\
FSH $(\mathrm{mIU} / \mathrm{mL})$ & $7.28 \pm 0.32$ & $7.36 \pm 0.28$ & 0.295 \\
$\mathrm{LH}(\mathrm{mIU} / \mathrm{mL})$ & $5.66 \pm 2.51$ & $6.32 \pm 2.03$ & 0.471 \\
$\mathrm{PRL}(\mathrm{ng} / \mathrm{mL})$ & $13.36 \pm 6.68$ & $14.18 \pm 8.26$ & 0.473 \\
$\mathrm{~T}(\mathrm{ng} / \mathrm{mL})$ & $0.66 \pm 0.16$ & $0.73 \pm 0.16$ & 0.421 \\
\hline
\end{tabular}

$\mathrm{E} 2$ = estrogen; $\mathrm{P}=$ progesterone; $\mathrm{FSH}=$ follicle stimulating hormone; $\mathrm{LH}=$ luteinizing hormone; $\mathrm{PRL}=$ prolactin; $\mathrm{T}=$ testosterone.

Table 2. Comparison of the age and induced abortion history in the two groups (means \pm SD).

\begin{tabular}{lcc}
\hline Group & Age (year) & Induced abortion numbers $(\mathrm{N})$ \\
\hline Case group & $30.6 \pm 3.1$ & $2.79 \pm 1.22$ \\
Control group & $29.2 \pm 3.3$ & $2.41 \pm 1.32$ \\
$\mathrm{P}$ & 0.081 & 0.498 \\
\hline
\end{tabular}

Table 3. Comparison of the endometrium thickness in the two groups (means $\pm \mathrm{SD}$ ).

\begin{tabular}{lccc}
\hline Group & Cases $(\mathrm{N})$ & Endometrial thickness $(\mathrm{mm})$ & $\mathrm{P}$ \\
\hline Case group & 120 & $4.35 \pm 0.40$ & $<0.001$ \\
Control group & 120 & $8.95 \pm 1.28$ & \\
\hline
\end{tabular}

The ER- $\beta$ 5th and 8th exons were amplified using PCR and digested with RsaI and $A l u \mathrm{I}$ restriction enzymes, respectively. RsaI genotypes $\mathrm{rr}, \mathrm{RR}$, and $\mathrm{Rr}$ appeared on DNA agarose electrophoresis as 1 large band, 1 small band, and 2 bands, respectively (Figure 1). AluI genotypes aa, AA, and Aa appeared as 1 band, 2 bands, and 3 bands, respectively (Figure 2).

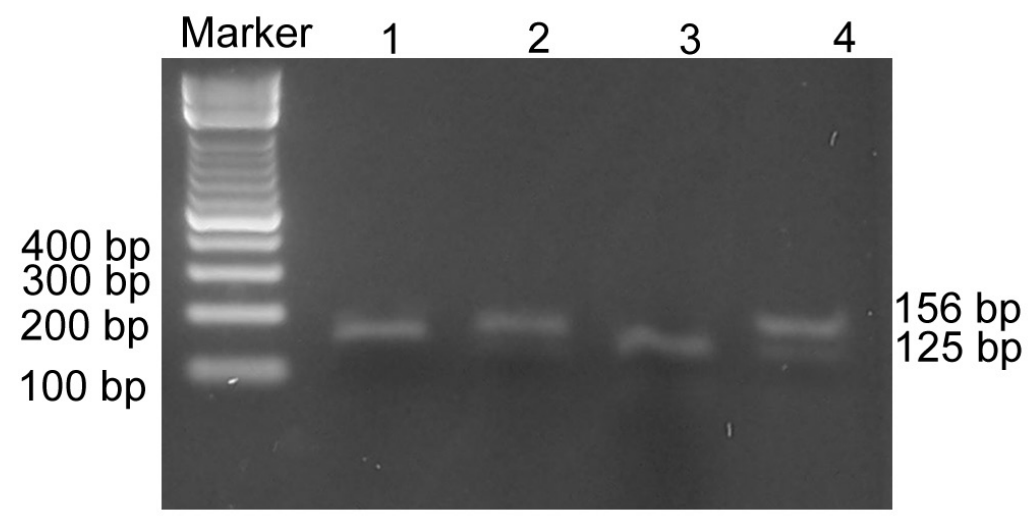

Figure 1. ER- $\beta$ fifth exon digestion with RsaI enzyme. Lane Marker = DNA marker; lane $1=$ null-enzyme digestion; lane 2 = rr genotype; lane $3=\mathrm{RR}$ genotype; lane $4=\mathrm{Rr}$ genotype. 


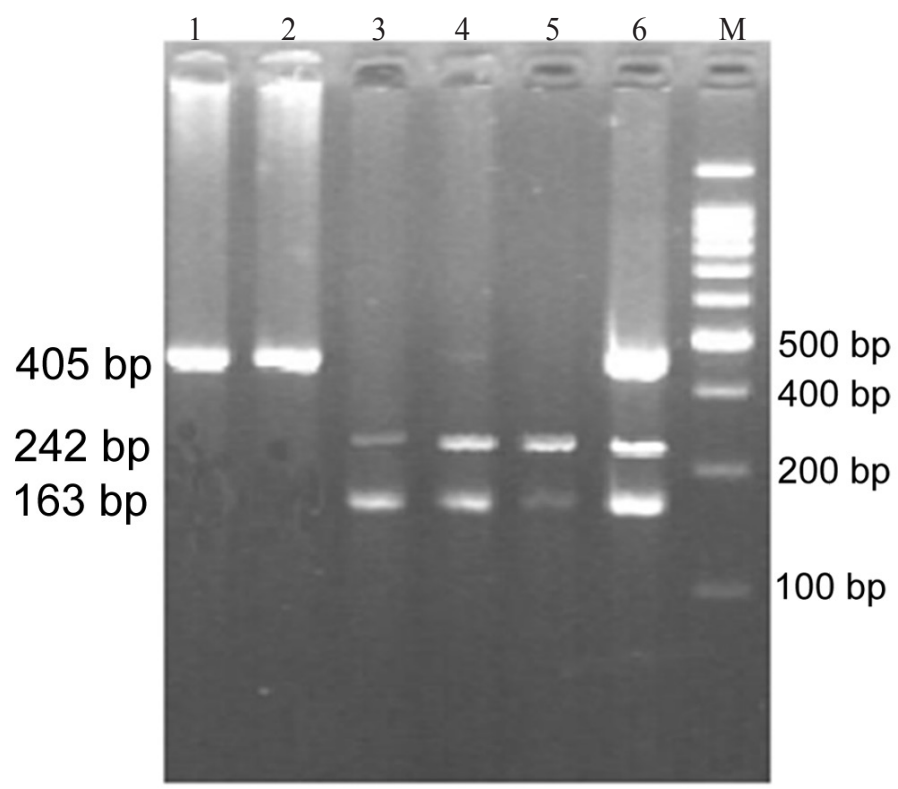

Figure 2. ER- $\beta$ eighth exon digestion with $A l u \mathrm{I}$ enzyme. Lane $M=$ DNA marker; lane $1=$ null-enzyme digestion; lane $2=$ aa genotype; lanes 3 to $5=\mathrm{AA}$ genotype; lane $6=$ Aa genotype.

The RR, Rr, and rr genotypic frequencies as well as the $\mathrm{R}$ and $\mathrm{r}$ allele frequencies of the $R s a \mathrm{I}$ polymorphism were significantly different between the 2 groups (Table 4 ). By contrast, the AA, Aa, and aa genotypic frequencies as well as the $\mathrm{A}$ and a allele frequencies of the AluI site were similar between the groups (Table 5).

Table 4. ER- $\beta$ gene RsaI polymorphism distribution and its relation with idiopathic thin endometrium.

\begin{tabular}{|c|c|c|c|c|c|c|c|c|}
\hline \multirow[t]{2}{*}{ Group } & \multicolumn{3}{|c|}{ Genotypic frequency } & \multicolumn{3}{|c|}{ Allele frequency } & \multirow[t]{2}{*}{$\chi^{2} / \mathrm{P}$} & \multirow[t]{2}{*}{ OR $(95 \% \mathrm{CI})$} \\
\hline & $\mathrm{RR}$ & $\mathrm{Rr}$ & $\mathrm{rr}$ & $\chi^{2} / \mathrm{P}$ & $\mathrm{R}$ & $\mathrm{r}$ & & \\
\hline Case group (120) & 14 & 61 & 45 & $6.759 / 0.034$ & 89 & 151 & $6.207 / 0.013$ & $0.630(0.438-0.907)$ \\
\hline Control group (120) & 25 & 66 & 29 & & 116 & 124 & & \\
\hline
\end{tabular}

Table 5. ER- $\beta$ gene $A l u$ I polymorphism distribution and its relation with idiopathic thin endometrium.

\begin{tabular}{|c|c|c|c|c|c|c|c|c|}
\hline \multirow[t]{2}{*}{ Group } & \multicolumn{3}{|c|}{ Genotypic frequency } & \multicolumn{3}{|c|}{ Allele frequency } & \multirow[t]{2}{*}{$\chi^{2} / \mathrm{P}$} & \multirow[t]{2}{*}{ OR $(95 \% \mathrm{CI})$} \\
\hline & AA & $\mathrm{Aa}$ & aа & $\chi^{2} / \mathrm{P}$ & A & $\mathrm{a}$ & & \\
\hline $\begin{array}{l}\text { Case group (120) } \\
\text { Control group (120) }\end{array}$ & $\begin{array}{l}5 \\
3\end{array}$ & $\begin{array}{l}34 \\
23\end{array}$ & $\begin{array}{l}81 \\
94\end{array}$ & $3.589 / 0.166$ & $\begin{array}{l}44 \\
29\end{array}$ & $\begin{array}{l}196 \\
211\end{array}$ & $3.635 / 0.057$ & $1.633(0.983-2.713)$ \\
\hline
\end{tabular}

In the current study, a D' value of $>0.3$ was considered to be the standard for the linkage analysis with SPSS13.0. The linkage disequilibrium between RsaI and AluI haploids was not significant in either group, with D' values of 0.2036 (Table 6) and 0.0685 (Table 7), respectively.

Relative risk analysis (95\% confidence interval) of the allele frequency (Table 8) showed that the $\mathrm{R}$ allele was associated with a risk for idiopathic thin endometrium lower 
than that of the $\mathrm{r}$ allele by 0.630 fold $(\mathrm{P}=0.013)$, whereas the frequency of the A allele had no significant contribution to the risk for the disease $(\mathrm{P}>0.05)$.

Table 6. ER- $\beta$ gene $R s a \mathrm{I}$ and $A l u$ I haplotype comparison in the idiopathic endometrium group.
\begin{tabular}{lcccccccc}
\hline Genotype & $\mathrm{R}$ & $\mathrm{r}$ & $\mathrm{D}$ & $\mathrm{D}^{\prime}$ & $\mathrm{r}^{2}$ & $\chi^{2}$ & $\mathrm{P}$ \\
\hline $\mathrm{A}$ & 32 & 12 & 0.0653 & 0.2036 & 0.1221 & 29.338 & $<0.001$ \\
a & 57 & 139 & & & & & \\
\hline
\end{tabular}

Table 7. ER- $\beta$ gene $R s a$ and $A l u$ I haplotype comparison in the control group.
\begin{tabular}{lcrrrrrr} 
Genotype & $\mathrm{R}$ & $\mathrm{r}$ & $\mathrm{D}$ & $\mathrm{D}$ & $\mathrm{D}^{2}$ & $\chi^{2}$ & $\mathrm{P}$ \\
\hline $\mathrm{A}$ & 21 & 8 & 0.0291 & 0.0685 & 0.0319 & 7.659 & 0.006 \\
a & 95 & 116 & & & & & \\
\hline
\end{tabular}

\begin{tabular}{lccc}
\multicolumn{2}{c}{ Table 8. Risk analysis of influential factor in idiopathic thin endometrium. } \\
\hline Influence factor & OR & $95 \% \mathrm{CI}$ & $\mathrm{P}$ \\
\hline Age & 0.555 & $0.158-0.937$ & 0.370 \\
FSH & 0.151 & $0.658-2.166$ & 0.717 \\
LH & 0.716 & $0.308-1.933$ & 0.652 \\
E2 & 1.138 & $0.315-3.944$ & 0.859 \\
PRL & 1.026 & $0.928-1.065$ & 0.297 \\
P & 0.968 & $0.874-1.098$ & 0.407 \\
T & 1.069 & $0.418-2.757$ & 0.937 \\
R allele & 0.63 & $0.438-0.907$ & 0.013 \\
A allele & 1.633 & $0.983-2.713$ & 0.057 \\
Rraa genotype & 0.846 & $0.480-1.491$ & 0.564 \\
RRaa genotype & 0.049 & $0.006-0.378$ & $<0.001$ \\
\hline
\end{tabular}

For abbreviations, see legend to Table 1.

\section{DISCUSSION}

ERs play an important role in the regulation of uterine endometrium, promoting the periodic vascular reconstruction of endometrium and facilitating the repair of endometrial hyperplasia (Mylonas et al., 2007). The ER mechanism is well documented. Briefly, ERs are associated with heat shock protein 90 in the cytoplasm as an inactive form that is activated and released from heat shock protein 90 on interaction with estrogen owing to 3-dimensional structural alterations. It thereby translocates into the nucleus, where it binds to DNA with high affinity, activating or inhibiting the transcription of the targeted genes (Ye et al., 2008). Nilsson et al. (2004) have suggested that single nucleotide polymorphisms of ERs might explain the dysfunction of the ER gene at the transcription and translation levels and ultimately lead to the malfunction of the estrogen and ER system in the uterus.

In the current study, we compared 2 groups without significant differences in serum sex hormone levels, age, and induced abortion history. They differed significantly in endometrium thickness. Hysteroscopy revealed the presence of a smooth and thin endometrium in the idiopathic thin endometrium group, which was confirmed with B ultrasound examination. The thickness of the endometrium is widely accepted to reflect its function and condition driven by estrogen, demonstrating periodic changes, proliferation, repair, and vascular reconstruction 
(Mansur Ade et al., 2005; Chae et al., 2009). However, some questions remain to be addressed in clinical practice, such as why does the normal endometrium of some patients ultimately turn into thin endometrium after an induced abortion, whereas that of others does not? Do individual genetic differences (gene polymorphisms) determine the susceptibility to certain diseases such as idiopathic endometrium? The ER- $\beta$ gene consists of 8 exons and 7 introns. The 2 most common polymorphisms have been found in the 5th exon, which codes for the ligand binding domain, and in the 8th exon, which corresponds to the 3 ' noncoding regions $R s a \mathrm{I}$ (-1082 G/A, rs1256049) and AluI (-1730 A/G, rs4986938) (Mansur Ade et al., 2005).

We found that the $R s a$ I genotype of the ER- $\beta$ gene was significantly different between the 2 groups. The risk of idiopathic thin endometrium with the $\mathrm{R}$ allele was lower than that with the $\mathrm{r}$ allele by $0.630(0.438-0.907)$ fold, indicating that the $\mathrm{R}$ allele might be a protective factor. The RsaI polymorphism is found at codon 328 , encoding valine, and corresponds to a synonymous mutation with no change at the protein level (Peng et al., 2003). Synonymous mutations have been postulated to influence gene transcription through several means (Setiawan et al., 2004): the local concentration of transfer RNA varies for different codons; the mutation on messenger RNA (mRNA) may induce the formation of hairpins and result in mRNA instability or transcriptional inactivity; or the polymorphism gives rise to linkage disequilibrium with the other site mutation, such as the polymorphism on the ER- $\beta$ gene $5^{\prime} \mathrm{G} 1082 \mathrm{~A}$ and $3^{\prime}$ untranslated region A1730G, which cross-links with the polymorphism on the splicing site of the 8th exon and affects the splicing of the 8th exon. Additionally, the polymorphism can induce an alteration in the secondary structure of ER- $\beta$ mRNA and lead to changes at the mRNA level, affecting synthesis, splicing, maturation, translocation, translation, and degradation, among other processes (Aschim et al., 2005; Ashton et al., 2009; Safarinejad et al., 2010).

The mechanism of the AluI polymorphism remains unclear. No significant differences were found in $A l u$ I genotype between the 2 groups. The relative risk analysis of the allele frequency indicated that the A allele might be irrelevant to idiopathic thin endometrium.

The linkage disequilibrium coefficient $\mathrm{D}^{\prime}$ and $\mathrm{r}^{2}$ are the 2 most commonly used paired test methods. The $\mathrm{D}^{\prime}$ value indicated that the linkage disequilibrium between the ER- $\beta$ RsaI and AluI polymorphisms was not significant, which was confirmed by the $\mathrm{r}^{2}$ values.

Overall, our study suggested that the R allele of the ER- $\beta$ gene might be a protective factor for idiopathic thin endometrium, although this conclusion must be confirmed by further studies based on a larger population database from multiple regions and nationalities. Further exploration of the influence of the AluI polymorphism of the ER- $\beta$ gene in the etiology of idiopathic endometrium is also of high interest. Future research should examine other ER gene sites and genetic polymorphisms.

\section{Conflicts of interest}

The authors declare no competing interests.

\section{ACKNOWLEDGMENTS}

Research supported by a grant from the Science Foundation and Bureau of Health of Chongqing City and the Natural Science Foundation of China (NSFC, \#81201720). 


\section{REFERENCES}

Aschim EL, Giwercman A, Stahl O, Eberhard J, et al. (2005). The RsaI polymorphism in the estrogen receptor- $\beta$ gene is associated with male infertility. J. Clin. Endocrinol. Metab. 90: 5343-5348.

Ashton KA, Proietto A, Otton G, Symonds I, et al. (2009). Estrogen receptor polymorphisms and the risk of endometrial cancer. BJOG 116: 1053-1061.

Chae YK, Huang HY, Strickland P, Hoffman SC, et al. (2009). Genetic polymorphisms of estrogen receptors $\alpha$ and $\beta$ and the risk of developing prostate cancer. PLoS One 4: e6523.

Detti L, Yelian FD, Kruger ML, Diamond MP, et al. (2008). Endometrial thickness dynamics and morphologic characteristics during pituitary downregulation with antagonists in assisted reproductive technology cycles. $J$. Ultrasound Med. 27: 1591-1596.

Goumidi L, Dahlman-Wright K, Tapia-Paez I, Matsson H, et al. (2011). Study of estrogen receptor-alpha and receptor- $\beta$ gene polymorphisms on Alzheimer's disease. J. Alzheimers. Dis. 26: 431-439.

Kovacs P, Matyas S, Boda K and Kaali SG (2003). The effect of endometrial thickness on IVF/ICSI outcome. Hum. Reprod. 18: 2337-2341.

Mansur Ade P, Nogueira CC, Strunz CM, Aldrighi JM, et al. (2005). Genetic polymorphisms of estrogen receptors in patients with premature coronary artery disease. Arch. Med. Res. 36: 511-517.

Momeni M, Rahbar MH and Kovanci E (2011). A meta-analysis of the relationship between endometrial thickness and outcome of in vitro fertilization cycles. J. Hum. Reprod. Sci. 4: 130-137.

Mylonas I, Jeschke U, Shabani N, Kuhn C, et al. (2007). Steroid receptors ER- $\alpha$, ER- $\beta$, PR-A and PR-B are differentially expressed in normal and atrophic human endometrium. Histol. Histopathol. 22: 169-176.

Nilsson M, Naessen S, Dahlman I, Linden HA, et al. (2004). Association of estrogen receptor $\beta$ gene polymorphisms with bulimic disease in women. Mol. Psychiatry 9: 28-34.

Peng B, Lu B, Leygue E and Murphy LC (2003). Putative functional characteristics of human estrogen receptor- $\beta$ isoforms. J. Mol. Endocrinol. 30: 13-29.

Richter KS, Bugge KR, Bromer JG and Levy MJ (2007). Relationship between endometrial thickness and embryo implantation, based on 1,294 cycles of in vitro fertilization with transfer of two blastocyst-stage embryos. Fertil. Steril. 87: 53-59.

Safarinejad MR, Shafiei N and Safarinejad S (2010). Association of polymorphisms in the estrogen receptors $\alpha$, and $\beta$ (ESR1, ESR2) with the occurrence of male infertility and semen parameters. J. Steroid Biochem. Mol. Biol. 122: 193-203.

Saha TK, Amer SA, Biss J, Thakare H, et al. (2004). The validity of transvaginal ultrasound measurement of endometrial thickness: a comparison of ultrasound measurement with direct anatomical measurement. BJOG 111: 1419-1424.

Setiawan VW, Hankinson SE, Colditz GA, Hunter DJ, et al. (2004). Estrogen receptor $\beta$ (ESR2) polymorphisms and endometrial cancer (United States). Cancer Causes Control. 15: 627-633.

Shapiro H, Cowell C and Casper RF (1993). The use of vaginal ultrasound for monitoring endometrial preparation in a donor oocyte program. Fertil. Steril. 59: 1055-1058.

Singh N, Bahadur A, Mittal S, Malhotra N, et al. (2011). Predictive value of endometrial thickness, pattern and subendometrial blood flows on the day of hCG by $2 \mathrm{D}$ doppler in in vitro fertilization cycles: A prospective clinical study from a tertiary care unit. J. Hum. Reprod. Sci. 4: 29-33.

Traub ML, Van Arsdale A, Pal L, Jindal S, et al. (2009). Endometrial thickness, Caucasian ethnicity, and age predict clinical pregnancy following fresh blastocyst embryo transfer: a retrospective cohort. Reprod. Biol. Endocrinol. 7 : 33.

Ye Y, Xiao Y, Wang W, Yearsley K, et al. (2008). ER- $\alpha$ suppresses slug expression directly by transcriptional repression. Biochem. J. 416: 179-187.

Yuan R and Le AW (2012). A study on the estrogen receptor alpha gene polymorphism and its expression in thin endometrium of unknown etiology. Gynecol. Obstet. Invest. 74: 13-20. 